\title{
Low-income Children's Participation in the National School Lunch Program and Household Food Insufficiency
}

\author{
Jin Huang ${ }^{1}$ and Ellen Barnidge ${ }^{1}$ \\ Author Affiliation: ${ }^{1}$ College for Public Health \& Social Justice, Saint Louis University, St. \\ Louis, Missouri \\ Correspondence: Jin Huang, PhD, School of Social Work, Saint Louis University, 3550 Lindell \\ Blvd., Tegeler Hall Room 211, St. Louis, MO 63103. \\ Telephone: 1-314-977-2750; Fax: 1-314-977-2730 \\ E-mail: jhuang5@slu.edu
}

Shortened Title: School Lunch Program and Food Insufficiency

Keywords: School Lunch, Food Hardship, Food Insufficiency, Food Insecurity

\section{Acknowledgements:}

The authors are grateful for support from the U.S. Department of Agriculture Research Innovation and Development Grants in Economics (RIDGE) through the Institute for Research on Poverty at University of Wisconsin-Madison and Saint Louis University President Research Fund and Faculty Leave Program. The content is solely the responsibility of the authors. 


\section{Low-income Children's Participation in the National School}

\section{Lunch Program and Household Food Insufficiency}

\section{ABSTRACT}

Assessing the impact of the National School Lunch Program (NSLP) on household food insufficiency is critical to improve the implementation of public food assistance and to improve the nutrition intake of low-income children and their families. To examine the association of receiving free/reduced-price lunch from the NSLP with household food insufficiency among low-income children and their families in the United States, the study used data from four longitudinal panels of the Survey of Income and Program Participation (SIPP; 1996, 2001, 2004, and 2008), which collected information on household food insufficiency covering both summer and non-summer months. The sample included 15, 241 households with at least one child (aged 5-18) receiving free/reduced-price lunch from the NSLP. A dichotomous measure describes whether households have sufficient food to eat in the observed months. Fixed-effects regression analysis suggests that the food insufficiency rate is $0.7(95 \% \mathrm{CI}: 0.1,1.2)$ percentage points higher in summer months among NSLP recipients. Since low-income families cannot participate in the NSLP in summer when the school is not in session, the result indicates the NSLP participation is associated with a reduction of food insufficiency risk by nearly $14 \%$. The NSLP plays a significant role to protect low-income children and their families from food insufficiency. It is important to increase access to school meal programs among children at risk of food insufficiency in order to ensure adequate nutrition and to mitigate the health problems associated with malnourishment among children.

Keywords: School Lunch, Food Assistance, Food Insufficiency, Food Insecurity 
INTRODUCTION

A growing number of children and their families in the United States face the risk of food

insufficiency, an important indicator of household food hardship (Alaimo, Olson, \& Frongillo, 2001) measuring whether families can get enough food for their members. Food insufficiency was the most commonly used indicator of household food hardship before the standardized Food Insecurity Scale (FIS) was developed by the US Department of Agriculture in the late 1990s. , The measure of food insufficiency is closest to the most severe form of food insecurity (very low food security) measured by the FIS (Nam, Huang, Heflin, \& Sherraden, 2015). In 2013, nearly $20 \%$ of households with children reported food insecurity (including both low and very low food security) at some time during the year (Coleman-Jensen, Gregory, \& Singh, 2014). Extensive literature has shown adverse impacts of inadequate food on children's nutritional, psychological, and educational outcomes (Alaimo, Olson, \& Frongillo, 2001; Gundersen \& Ziliak, 2014;

Kleinman et al., 1998; Rose-Jacobs et al., 2008; Roustit et al., 2012; Weinreb et al., 2002; Whitaker, Phillips, \& Orzol, 2006).

To ensure adequate nutrition among low-income, school-aged children, several federallyfunded food assistance programs target this vulnerable population, including the Supplemental Nutrition Assistance Program (SNAP), the NSLP, the School Breakfast Program (SBP), and the Summer Food Service Program (SFSP). The present study specifically focuses on the NSLP and examines its association with household food insufficiency. As one of the largest nutrition assistance programs for school-aged children in the United States, the NSLP operates in public schools, nonprofit private schools, and residential child care institutions. The NSLP costs roughly $\$ 11.6$ billion a year and provides nutritional and low-cost or free lunches to more than 31 million children (USDA Food and Nutrition Service, 2012). Children from families with 
47 income at or below $130 \%$ of the US federal poverty level are eligible for free meals; those from 48 families with income between $130 \%$ and $185 \%$ of the poverty level are eligible for reduced-price meals at a rate of less than 40 cents (USDA Food and Nutrition Service, 2012). In the 2002-2003 50 school year, nearly three quarters of eligible children received the benefits of free/reduced-price

51 lunch (Dahl \& Scholz, 2011). It is estimated that more than 21 million, or $39 \%$ of all school-age 52 children, receive a free/reduced-price lunch from the NSLP (Bartfeld, 2013). affect households' food insecurity or insufficiency (Arteaga \& Heflin, 2014; Bartfeld \& Dunifon, 2006; Bartfeld, Kim, Ryu, \& Ahn, 2009; Bartfeld \& Ryu, 2011; Gao, Ishdorj \& Higgins, 2012; Gundersen, Kreider, \& Pepper, 2012; Kabbani \& Kemid, 2005). If the program reduces lowincome caregivers' expenditure on children's food consumption, it may lower the risk of food insufficiency for the household through transfer of resources to other members' food consumption. The empirical literature has suggested the NSLP participation is associated with higher odds of having adequate food among school-age children (Arteaga \& Heflin, 2014; Gundersen, Kreider, \& Pepper, 2012; Kabbani \& Kmeid, 2005), with some inconsistent findings from other research (Gao, Ishdorj \& Higgins, 2012). Gunderson et al. (2012) found that NSLP participation was associated with a reduction of 6 percentage points in low household food security. Using the kindergarten cut-off age as an instrumental variable, Arteaga and Heflin (2014) suggested that children who received free/reduced-price lunch through the NSLP had a much lower probability of food insecurity compared to households whose children paid for their own lunch. A third study (Kabbani \& Kmeid, 2005) showed that the NSLP may provide a greater protection to those receiving a free lunch than to those receiving a reduced price lunch. Another one (Gao, Ishdorj, \& Higgins, 2012) instead used whether students had enough time to eat school 
70 lunch or not as an instrumental variable but did not find a significant association between the

71 NSLP and food insecurity.

72 One common challenge to assess the impact of food assistance programs on food

73 insufficiency is a potential selection bias that households without enough food are more likely to

74 participate in these programs (Nord \& Golla, 2009). In general regression analyses, the program

75 participation variable often is positively associated with food insufficiency due to this bias (Nord

76 \& Golla, 2009). The NSLP provides services during the school year but not summer months

77 when school is not in session. The unavailability of the NSLP program in summer is not caused

78 by parents' self-selection. The seasonal pattern of the NSLP participation is not correlated with

79 parents' self-selection, and, therefore, is useful to address the selection bias in nutrition

80 assistance program evaluation. If the NSLP participation reduces the risk of food insufficiency,

81 households eligible for the NSLP benefits are more likely to experience food insufficiency in the

82 summer when the NSLP is not available.

83 There are two potential limitations of this strategy due to confounding factors. The

84 seasonal difference in the NSLP participation may be confounded with other seasonal trends,

85 such as child care arrangement and employment status in summer (Brady, Sprague, Gey,

86 Wiseman, 2002; Capizzano, 2002). A second potential confounder is the Summer Food Service

87 Program (SFSP) and related Seamless Summer Option (SSO) which are entitlement programs

88 offering free meals and snakes to low-income children in the summer when school is not in

89 session (US Department of Agriculture, 2015). These summer meal programs are small relative

90 to the NSLP. In fiscal year 2014, an average of 2.5 million children participated in the SFSP

91 daily, with a total federal cost of \$464 million (US Department of Agriculture, 2015). Some 
92 NSLP recipients may utilize summer meal programs and reduce their risk of food insufficiency

93 in summer.

Despite these limitations, the seasonal difference in the NSLP participation seems a

95 promising strategy to identify program impacts. Few studies have taken advantage of this feature on program participation to assess the NSLP impacts on food insecurity or insufficiency. Based

97 on a cross-sectional design, Nord and Roming (2006) defined September as the summer month and found a lower level of food security in summer for households with children than those without a child. The study only used September as the summer month because data in other summer months were not available. Another study (Huang, Barnidge, \& Kim, 2015) applied growth-curve analyses to describe trajectories of food insufficiency over time for both the NSLP

102 recipients and eligible nonrecipients. It suggested an increase of food insufficiency rate in summer for the NSLP recipients but not for eligible nonrecipients. Based on previous literature,

104 we test the association between the seasonal variation in the NSLP participation and food 105 insufficiency among those receiving free/reduced-price lunches. Our study defines summer months as June, July, and August and uses individual households' longitudinal data over four

107 calendar months. We apply a fixed-effects model on longitudinal household data to control for 108 the unobserved selection bias.

109 METHODS

\section{Data and Sample}

We used data from four panels $(1996,2001,2004$, and 2008) of the SIPP, a longitudinal 112 and nationally representative household survey operated by the U.S. Census Bureau with sample 113 size ranging from about 37,000 to 52,000 households (US Census Bureau, 2001). The detailed 114 information of the SIPP can be found at the webpage of http://www.census.gov/sipp/. In each 
115 panel, the SIPP followed the same households in multiple waves of interviews. There were 12 116 waves for the 1996 and 2004 panels, 9 waves for the 2001 panel, and 16 panels for the 2008

117 panel. The time interval between each pair of waves was four months, and each interview then

118 collected information in the last four months (i.e., the reference period of each wave). In order to

119 ease the data collection process and spread the work evenly, the SIPP sample was randomly

120 divided into four rotation groups with nearly equal size. Each rotation group was interviewed in a

121 separate month, and the same wave of interviews thus was conducted in four consecutive

122 calendar months for these rotation groups, respectively. The reference period of each wave

123 covered different calendar months for four rotation groups. For instance, the 1996 SIPP panel has

12412 waves of interviews conducted from April 1996 to March 2000. As shown in Table 1, the

125 wave 8 interview of the 1996 panel was conducted in August 1998 for the first rotation group to

126 collect information from April to July. The same interview was conducted instead in November

1271998 for the fourth rotation group to collect information from July to October.

Since the 1996 panel, the SIPP included a household food insufficiency question in at

129 least one wave of interviews (see Table 1). Given the survey feature that four rotation groups had

130 different calendar months as the reference period, the SIPP thus collected the information on

131 food insufficiency across seven calendar months for four groups together. If summer months

132 were defined as June, July, and August (months 6-8 in Table 1), the first rotation group of the

1331996 panel had the information on food insufficiency from April to July, including two summer

134 months, while the second group had the information from May to August with three summer 135 months.

We created a sample including households with children aged 5-18 years and with at least 137 one child receiving free/reduced-price lunch from the NSLP one wave before the information of 
138 food insufficiency was collected. We did so because the number of summer months in the wave 139 when the information of food insufficiency was collected may affect children's NSLP

140 participation status and household food insufficiency simultaneously in that wave, and becomes

141 a confounding factor for evaluating the NSLP impact. For example, the information of food

142 insufficiency was collected in wave 8 of the 1996 panel, and we used the information in wave 7

143 to select recipients of free/reduced-price lunch. A household with a child receiving free/reduced144 price lunch from the NSLP in wave 7 may have reported nonparticipation if its reference period

145 for wave 8 includes multiple summer months (e.g., the third rotation group in the 1996 panel).

146 Therefore, the sample selection based on the NSLP participation status in the wave when food

147 insufficiency information was collected may exclude recipient households. The exclusion of 148 these recipient household is likely to generate underestimated effects of the NLSP participation 149 on food insufficiency

150 Combining four SIPP panels, the final sample included 15,241 households, referred to as 151 recipients of free/reduced-price lunch below. Using the 1996 panel as an example, there were 15228,168 households interviewed in wave 7 and 2,592 having at least one child receiving 153 free/reduced-price lunch. Among these recipients, $145(5.6 \%)$ had no valid information in wave 154 8. The final sample for this panel is 2,447 households with children. Similarly, only a small 155 proportion of recipients of free/reduced-price lunch in other panels were excluded due to missing 156 values. The last two columns of Table 1 report the number of households and number of monthly 157 observations for each rotation group in four SIPP panels.

$158 \quad$ Measures

Outcome Measure. To collect information on household food insufficiency, the SIPP 160 asked respondents to choose the statement best describing the food eaten in the household in the 
161 last four months: "enough of the kinds of food we want", "enough but not always the kinds of

162 food we want", "sometimes not enough to eat", and "often not enough to eat". Households

163 reporting "sometimes" or "often" not enough to eat were coded as " 1 " on a dichotomous

164 indicator of the four-month food insufficiency, and others are coded as " 0 ". For those with

165 responses that indicate food insufficiency in the last four months (i.e., households with the value

166 " 1 " on the four-month food insufficiency indicator), the SIPP further asked respondents in which

167 month during the reference period they experienced food insufficiency, and thus provides

168 monthly information about food insufficiency in four consecutive calendar months for each

169 household. A dichotomous indicator of household monthly food insufficiency (Yes $=1$ and No $=$

170 0) was generated. For example, each household has four data observations for the wave of

171 interview, one for each calendar month in the reference period. If the household suffered from

172 food insufficiency in the first calendar month only, the household had a positive response on the

173 monthly food insufficiency indicator in the first observation, but not the other three. At the same

174 time, this household had a positive response on the four-month food insufficiency indicator in all

175 four observations.

176

Independent Variable. A dichotomous measure of summer month (Yes $=1$ and No $=0)$

177 was created for each calendar month in the reference period. The calendar month between June

178 and August was considered summer months, and others were defined as non-summer months.

179 Covariates. The study included characteristics of households and household heads as

180 control variables in different analyses. Household characteristics were household size, household

181 monthly income, metro status (living in metro areas or not), the participation of Supplemental

182 Nutrition Assistance Program (SNAP), and public housing status (whether receiving public

183 housing benefits or not). Household head's characteristics included age, gender, race (White, 
184 Black, and others), marital status (married or not), education (below high school, high school, 185 some college, and bachelor and above), employment status (employed or not). In some analyses, 186 we also controlled for the order of the reference month (i.e., the first, second, third, or fourth 187 month in the reference period), indicators of states, and indicators of interview years. All 188 analysis variables were drawn from the wave when household food insufficiency information 189 was collected.

190 Statistical Analysis

Since the SIPP data had the longitudinal information of food insufficiency in four 192 months, the association between the NSLP participation and food insufficiency was estimated by 193 a fixed-effects OLS regression model:

$$
Y_{i t}=\alpha_{i}+\beta s_{i t}+\gamma m_{i t}+X_{i t} \delta+\varepsilon_{i t} \quad \text { for } t=1, \ldots, 4 \text { and } i=1, \ldots, N
$$

where $Y_{i t}$ is the monthly food insufficiency indicator for household $i$ at month $t ; \alpha_{i}$ is the 196 unobserved time-invariant individual effect; sit is a dichotomous summer month indicator for 197 household $i$ at month $t$; $m_{i t}$ is the order of the reference month (first, second, third, or fourth) for 198 household $i$ at month $t ; X_{i t}$ is time-variant control variables, including demographic and 199 socioeconomic characteristics; and $\varepsilon_{i t}$ is the error term. We controlled for the order of the 200 reference month, because participants reported monthly food insufficiency status for four 201 previous months at the interview time and may have more accurate information on food 202 insufficiency for the month closer to the interview. Most covariates on characteristics of 203 households and household heads remained the same in the short observation period of four 204 months; the number of time-variant control variables included in fixed-effects analyses thus was 205 relatively small. 
The parameter of interest is the regression coefficient of the summer month indicator, $\beta$,

207 which indicates the average change in the probability of food insufficiency from non-summer

208 months to summer months for a household with a recipient of free/reduced-price lunch. If the

209 NSLP reduces food insufficiency, $\beta$ will be statistically significant and positive: Recipients and

210 their households are more likely to be food insufficient in summer months when the program is

211 not available.

212 We conducted four sensitivity tests. First, we used a different definition of summer

213 months and considered July as the only summer month in the reference period, because children

214 in some states may not be completely out of school session in the calendar months of June and

215 August. Second, we reran the analysis to a smaller sample, recipients with household income

216 lower than $130 \%$ of the poverty line and examined the association between the NSLP

217 participation and food insufficiency among those eligible for free lunch. The impact of the NSLP

218 participation may vary by whether children received free or reduced-price lunch. Third,

219 assuming that the NSLP participation may have various impacts for children with different ages,

220 we tested the model on two separate samples - households with at least one child aged 5-11 and

221 those with at least one child aged 12-18. Finally, disregarding the longitudinal nature of the data,

222 we used pooled cross-sectional analyses in OLS and Logit regressions to include time-invariant

223 covariates. Results from these sensitivity tests are similar to those from main analyses. All

224 analyses were adjusted with the sampling weight variable generated by the SIPP for the

225 households in the wave when food insufficiency information was collected.

226 RESULTS

227 Sample Characteristics 
Table 2 reports weighted characteristics of sample households. In the observation period 229 of four months, nearly $7 \%$ of recipient households suffer from food insufficiency; in any given month during this four-month period, the food insufficiency rate is 3.9\%. Food insufficiency rates by calendar month and rotation group are reported in Table 1. For example, the mean food

232 insufficiency rate is $5.34 \%(\mathrm{SE}=.009)$ for the first rotation group of the 1996 panel and $3.79 \%$

$233(\mathrm{SE}=.007)$ for the second rotation group increases to $4.00 \%$ and $5.34 \%$ in August 1998 ,

234 respectively. While there are some discrepancies on monthly food insufficiency rates in summer 235 months across rotation groups, the inter-rogation group difference generally is not statistically 236 significant in our sample.

Also reported in Table 2, aggregated over four panels, the mean age of household heads 238 is about 40, and nearly two-thirds of heads are female, white, and employed. About half of 239 household heads are married, and less than 10\% have a college degree. On average, the 240 household size is 4.3. Nearly three quarters of households live in metro areas, and average 241 monthly household income is $\$ 2,800$. Less than $40 \%$ of households receive SNAP benefits, and 242 less than $10 \%$ participate in public housing programs.

243 Food Insufficiency across Calendar Months

Figure 1 presents food insufficiency rates among recipient households from January to

245 October aggregated over four SIPP panels. As shown in the solid line, the average monthly food 246 insufficiency rate stays at about 3.5\% from January to May, and increases in summer months$2474.3 \%$ in June, $4.6 \%$ in July, and 3.9\% in August. However, different from our hypothesis, the 248 food insufficiency rate continues to increase after summer months $-4.6 \%$ in September and $5.0 \%$ 249 in October. One possible explanation is that only the 1996 panel, which has a higher food 250 insufficiency rate than recent panels, includes September and October in the reference period. 
251 Table 1 shows that the fourth rotation group in the 1996 panel includes both September and

252 October in its reference period and the third rotation group in the 1996 panel includes September

253 in the reference period. We further present food insufficiency rates excluding these two rotation

254 groups in the dotted line, which has a pattern of food insufficiency consistent with our hypothesis.

255 Results of Regression Analyses

256 Results of fixed-effects analyses on recipients of free/reduced lunch are presented in

257 Table 3. As shown in the first column, the dichotomous indicator of summer months is positively

258 related to the probability of food insufficiency $(b=.007 ; 95 \% \mathrm{CI}: .001, .012)$, statistically

259 significant at the .01 level. The result suggests that the monthly food insufficiency rate is 0.7

260 percentage points higher in summer months for households with children receiving free/reduced-

261 price lunch. This model only includes the order of four reference months as a control variable,

262 and does not adjust demographic and socioeconomic covariates. We add several time-variant

263 control variables in the second column, including household heads' employment and marital

264 status and monthly household income. Since the reference period covers a short period of time

265 (four months), many variables the SIPP collects do not change within the household unit during

266 these four consecutive calendar months, and cannot be included in the fixed-effect analysis.

267 Result in the second column $(b=.007 ; 95 \% \mathrm{CI}: .001, .012 ; \mathrm{p}<.01)$ is consistent with that in the

268 first one.

269 Four sensitivity tests obtain consistent results on the association between the NSLP

270 participation and household food insufficiency. If we define July as the only summer month, the

271 monthly food insufficiency rate is 0.7 percentage points higher in July than other non-summer

272 months (the third column of Table $3 ; \mathrm{b}=.007 ; 95 \% \mathrm{CI}: .001, .012 ; \mathrm{p}<.01$ ). The magnitude of the

273 regression coefficient on the summer month indicator becomes slightly smaller $(b=.005 ; 95 \% \mathrm{CI}$ : 
$274.000, .010 ; \mathrm{p}<.05)$ when the model is tested only on households eligible for free lunch (the fourth

275 column of Table 3). Similarly, the regression coefficient of the summer month indicator is

276 positive and statistically significant for the sub-sample of households with children aged 5-11 or

277 those with children aged 12-18.

278

The pooled OLS analysis, reported in the seventh column, controls for both time-variant

279 and time-invariant characteristics of households and household heads. It has similar results

$280(b=.007 ; 95 \% \mathrm{CI}: .002, .012 ; \mathrm{p}<.01)$ to those of fixed-effect OLS analyses, probably because the

281 summer month indicator is not related to any demographic and socioeconomic characteristics,

282 and recipients of free/reduced-price lunch are relatively homogenous. The pooled OLS analysis

283 in Table 3 does not adjust for households' SNAP participation status as it is likely to carry the

284 selection bias demonstrated in previous studies. If we do add it in the analysis, the indicator of

285 SNAP participation is positively associated with food insufficiency $(b=.007 ; 95 \% \mathrm{CI}: .002, .012$;

$286 \mathrm{p}<.01)$ but does not change the result on the summer month indicator. Another sensitivity test,

287 the logit analysis in the eighth column, shows higher odds of food insufficiency in summer

288 months $(\mathrm{OR}=1.21 ; 95 \% \mathrm{CI}: 1.07,1.37 ; \mathrm{p}<.01)$ for recipients of free/reduce-price lunch.

289 DISCUSSION

To assess the association of the NSLP participation and household food insufficiency, the

291 study uses the seasonal difference in the NSLP participation to address the potential selection

292 bias. Fixed-effect analyses do not show a positive association between household food

293 insufficiency and receiving free/reduced-price lunch from the NSLP, which implies that the

294 seasonal difference in the NSLP participation is a valid identification strategy to control for the

295 potential selection bias. Results reported in Table 3 suggest that regression coefficients of the

296 summer month indicator in general are similar across fixed-effects and other sensitivity analyses 
297 and are similar across models control and do not control for demographic and socioeconomic

298 characteristics. This demonstrates that the indicator of summer months is not associated with

299 individual behaviors and, therefore, is not affected by households' self-selection into the NSLP.

300 The study finds that the NSLP reduces food insufficiency among low-income households with

301 children. In summer months when the NSLP is not available, the food insufficiency rate among

302 recipients is about 0.7 percentage points higher than that in non-summer months. Since the

303 average monthly food insufficiency rate is $3.9 \%$ in the sample, our finding indicates that the

304 NSLP participation is associated with a $14 \%$ reduction in the risk of experiencing food

305 insufficiency.

306 Several limitations of this study should be noted. First, as mentioned above, the summer

307 month variable may be confounded by other seasonal trends. Food insufficiency may occur less

308 frequently if caregivers are more likely to have a job or food prices are lower in summer. Food

309 insufficiency in summer months may be associated with household expenditures when school is

310 out of session. Families may have different child care costs or utility bills because people are in

311 the home more often. For example, it has been found that, relying more on relative care, low-

312 income families spend less on child care during the summer compared to the school year

313 (Capizzano, 2002). In agricultural counties and rural areas, low-income families' participation in

314 welfare programs increases dramatically from summer to winter (Brady, Sprague, Gey, Wiseman,

315 2002); there are more seasonal jobs available for low-income families in summer, and it may

316 protect them from food hardship as well. Nonetheless, one recent study (Huang, Barnidge, \&

317 Kim, 2015) provided indirect evidence that the association between the NSLP participation and

318 food insufficiency may not be affected by those confounders mentioned above. Using a growth-

319 curve analysis to describe the seasonal trends of food insufficiency for both the NSLP recipients 
and eligible nonrecipients, the study suggested that eligible nonrecipients did not experience an increase in food insufficiency in summer. It further compared the differences in food insufficiency between summer and non-summer months for both groups and found a greater risk of food insufficiency in summer for the NSLP recipients. Second, our result may overestimate the NSLP impact if it also carries the impact of other school meal programs such as the School Breakfast Program. Alternatively, it may underestimate the NSLP impact as well since we do not control for participation in summer meal programs. Third, reporting accuracy of program participation in the SIPP data is difficult to assess. Parents may overreport their children's participation in school meal programs, in particular for the School Breakfast Program (Bartfeld, 2013). Another data issue shown in Table 1 is the inter-rotation group difference in monthly food insufficiency rates, and should be explored in future research as well.

Nonetheless, a 14\% reduction in the risk of household food insufficiency seems substantial, in particular, given that the program targets children only. The findings suggest that the NSLP plays a significant role in protecting low-income families from food insufficiency. Yet, there is opportunity to further increase access to school meal programs among risky children (Frentz \& Neuberger, 2012). Our analysis of the SIPP data suggests that nearly $70 \%$ of children eligible for free/reduced-price lunch received such benefits in the 2008 SIPP panel. Although one study (US Department of Agriculture, 2009) shows that states are not enrolling many incomeeligible children into the NSLP, implementation of new policy tools in recent years suggests progress (US Department of Agriculture, 2013). Categorical eligibility allows children to receive free school meals if they are in foster care, Head Start, homeless, or living in a household receiving TANF benefits. Direct certification requires schools operating the NSLP to directly certify children for free meals if their families receive SNAP benefits. Among children eligible 
343 for the direct certification process, the certification rate increased from $68 \%$ in the school year $344 \quad 2007-2008$ to $89 \%$ in the school year 2012-2013. As a new policy option in the 2013-2014 345 school year, community eligibility allows schools to provide free meals to all students if schools 346 have $40 \%$ or more students directly certified for the program. Community eligibility eliminates 347 the need for individual enrollment and increases access to school lunch for all children.

348 The higher food insufficient rate in summer months among recipients of free/reduced349 price lunch also suggests that it is important to provide nutrition assistance to low-income 350 children in summer when school is not in session. Both the Summer Food Service Program 351 (SFSP) and the Summer Seamless Option (SSO) were established by the US Department of 352 Agriculture to continue the provisions of nutrition assistance to low-income children in the 353 summer. Currently, participation in the SFSP and the SSO is much lower than participation in 354 the NSLP and the SBR; therefore, these programs should be expanded and applied to all children 355 at risk of food insufficiency. 


\section{REFERENCES}

357 Alaimo, K, Olson, C. M., \& Frongillo, E. A. (2001). Food insufficiency and American schoolaged children's cognitive, academic, and psychosocial development. Pediatrics, 108(1), 44-53.

360 361

362

Arteaga, I., \& Heflin, C. (2014). Participation in the National School Lunch Program and food security: An analysis of transitions into kindergarten. Children and Youth Services Review, 47, 224-230.

Bartfeld, J. (2013). SNAP and the School Meal Programs. University of Kentucky Center for Poverty Research Discussion Paper Series, DP2013-08. Lexington, KY: Center for Poverty Research, University of Kentucky.

Bartfeld, J., Dunifon, R. (2006). State-level predictors of food insecurity and hunger among households with children. Journal of Policy Analysis and Management, 25(4), 921-941.

Bartfeld, J., Kim, M., Ryu, J., \& Ahn, H. (2009). The School Breakfast Program: Participation and impacts. ERS Contractor and Cooperator Report No. 54. Washington, D.C.: US Department of Agriculture.

Bartfeld, J. S., \& Ryu, J. H. (2011). The School Breakfast Program and breakfast-skipping among Wisconsin elementary school children. Social Service Review, 85(4), 619-634.

Brady, H., Sprague, M., Gey, F. C., \& Wiseman, M. (2002). Seasonal employment dynamics and welfare use in agricultural and rural California counties. In B.A. Weber, G. J. Duncan, \& L. A. Whitener (Eds.), Rural dimensions of welfare reform (pp.147-176). Kalamazoo, Michigan: W.E. Upjohn Institute for Employment Research. 
377 Capizzano, J. (2002). What happens when the school year is over?: The use and costs of child

378

379

380

381

382

383

384

385

386

387

388

389

390

391

392

393

394

395

396

397

398

399 care for school-age children during the summer months. Washington, D.C.: Urban Institute.

Coleman-Jensen, A., Gregory, C., \& Singh, A. (2014). Household food security in the United States in 2013. Washington, D.C.: U.S. Dept. of Agriculture, Economic Research Service.

Dahl, M. W., \& Scholz, J. K. (2011). The National School Lunch Program and School Breakfast Program: Evidence on participation and noncompliance. Madison, WI: Institute for Research on Poverty, University of Wisconsin-Madison.

Frentz, N., \& Neuberger, Z. (2012). Key steps to improve access to free and reduced-price school meals. Washington, D.C.: Center on Budget and Policy Priorities.

Gundersen, C., Kreider, B., \& Pepper, J. (2012). The impact of the National School Lunch Program on child health: A nonparametric bounds analysis. Journal of Econometrics, 166(1), 79-91.

Gao X, Ishdorj A, \& Higgins L. (2012). Impact of the national school lunch program on children's food security. College Station, TA: Texas A\&M University, Department of Agricultural Economics.

Gundersen, C., \& Ziliak, J. P. (2014). Childhood food insecurity in the US: Trends, causes, and policy options. The Research Report of Future of Children. Princeton, NJ: Princeton University.

Huang, J., Barnidge, E., \& Kim, Y. (2015). Children Receiving Free or Reduced-Price School Lunch Have Higher Food Insufficiency Rates in Summer. Journal of nutrition, 145(9), 2161-2168. 
400

401

402

403

404

405

406

407

408

409

410

411

412

413

414

415

416

417

418

419

420

Kabbani, N. S., \& Kmeid, M. Y. (2005). The role of food assistance in helping food insecure households escape hunger. Applied Economic Perspectives and Policy, 27(3), 439-445.

Kleinman, R. E, Murphy, J. M., Little, M., Pagano, M., Wehler, C. A., Regal, K., Jellinek, M. S. (1998). Hunger in children in the United States: Potential behavioral and emotional correlates. Pediatrics, 101(1), e3-e3.

Nam, Y., Huang, J., Heflin, C., \& Sherraden, M. (2015). Racial and ethnic disparities in food insufficiency: Evidence from a statewide probability sample. Journal of the Society for Social Work and Research, 6(2), 201-228.

Nord, M., Golla, A. M. (2009). Does SNAP decrease food insecurity? Untangling the self-section effect. ERS Economic Research Report no.85. Washington, D.C.: U.S. Department of Agriculture.

Nord, M., \& Roming, K. (2006). Hunger in the summer. Journal of Children Poverty, 12(2), $141-158$.

Rose-Jacobs, R., Black, M. M., Casey, P. H., Cook, J. T., Cutts, D. B., Chilton, M., Frank, D. A. (2008). Household food insecurity: Associations with at-risk infant and toddler development. Pediatrics, 121(1), 65-72.

Roustit, C., Hamelin, A. M., Grillo, F., Martin, J., Chauvin, P. (2012). Food insecurity: Could school food supplementation help break cycles of intergenerational transmission of social inequalities? Pediatrics, 126(6), 1174-1181.

US Census Bureau. (2001). Survey of Income and Program Participation User's Guide (3rd Edition). Washington, D.C.: U.S. Census Bureau, 2001. 
421 USDA Food and Nutrition Service. (2009). Direct certification in the National School Lunch

422

423

424

425

426

427

428

429

430

431

432

433

434

435

436

437

438
Program: State implementation progress: Report to Congress. Alexandria, VA: US

Department of Agriculture, Food and Nutrition Service.

USDA Food and Nutrition Service. (2012). National School Lunch Annual Survey: Updated August 2012. Alexandria, VA: US Department of Agriculture, Food and Nutrition Service.

USDA Food and Nutrition Service. (2013). Direct certification in the National School Lunch Program: State implementation progress, school year 2012-2013: Report to Congress. Alexandria, VA: US Department of Agriculture, Food and Nutrition Service.

USDA Food and Nutrition Service. (2015). Program Information Report (Keydata) U.S. Summary, FY 2014 - FY 2015. Alexandria, VA: US Department of Agriculture, Food and Nutrition Service. http://www.fns.usda.gov/sites/default/files/datastatistics/KeydataJanuary-2015.pdf (accessed May2015).

Weinreb, L., Wehler, C., Perloff, J., Scott, R., Hosmer, D., Sagor, L., Gundersen, C. (2002). Hunger: Its impact on children's health and mental health. Pediatrics, 110(4), e41-e41.

Whitaker, R. C., Phillips, S. M., Orzol, S. M. (2006). Food insecurity and the risks of depression and anxiety in mothers and behavior problems in their preschool-aged children. Pediatrics, 118(3), e859-e868. 
Table 1. Calendar Months for the SIPP Wave with Food Insufficiency Information

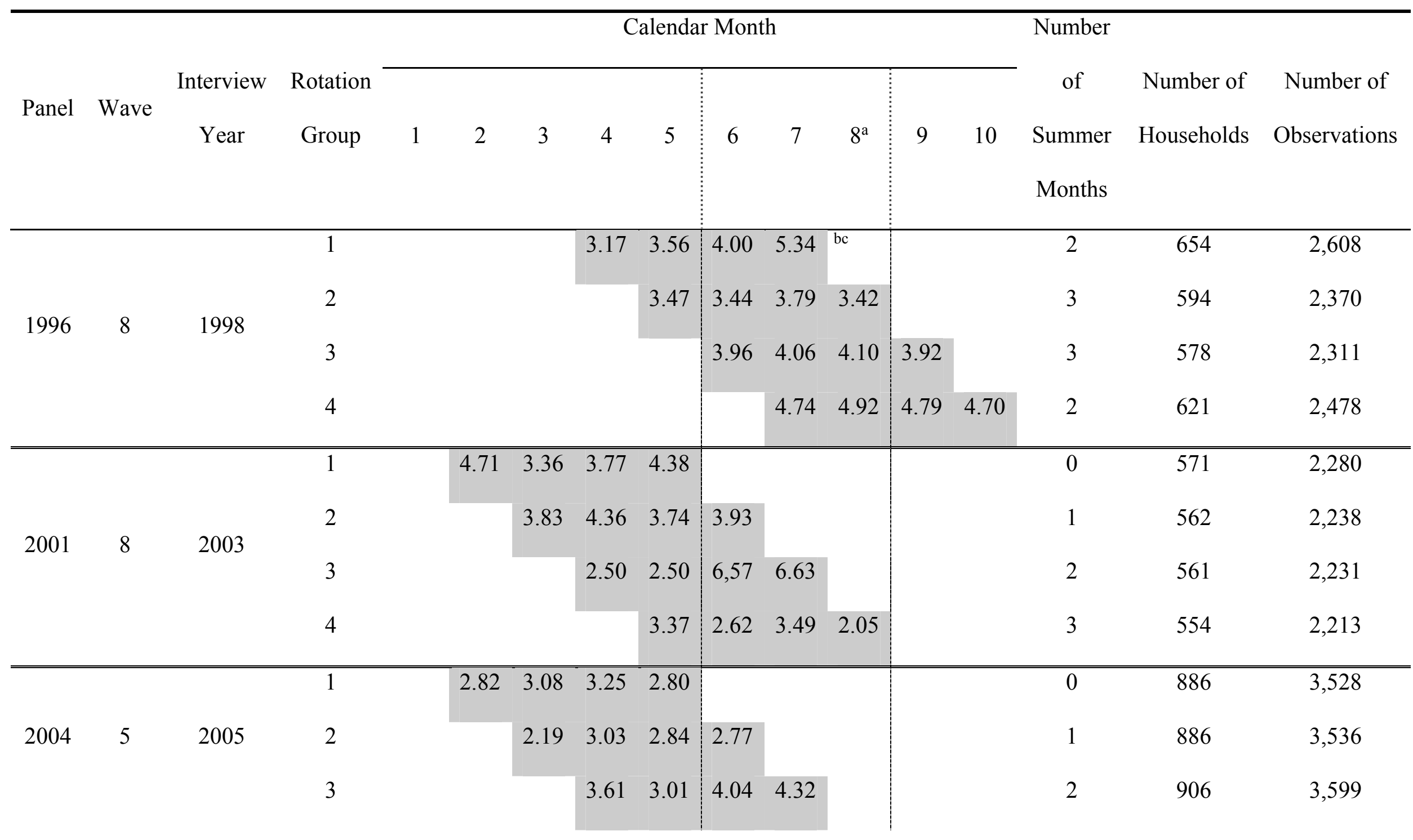




\begin{tabular}{|c|c|c|c|c|c|c|c|c|c|c|c|c|c|}
\hline & & & 4 & & & & & 3.53 & 3.97 & $5.09 \quad 5.20$ & 3 & 892 & 3,561 \\
\hline \multirow{4}{*}{2008} & \multirow{4}{*}{6} & \multirow{4}{*}{2010} & 1 & 2.79 & 2.49 & 3.04 & 2.99 & & & & 0 & 888 & 3,537 \\
\hline & & & 2 & & 2.82 & 2.78 & 2.80 & 2.74 & & & 0 & 896 & 3,574 \\
\hline & & & 3 & & & 3.72 & 4.04 & 4.53 & 4.08 & & 1 & 948 & 3,778 \\
\hline & & & 4 & & & & 3.34 & 2.81 & 3.84 & 4.41 & 2 & 863 & 3,450 \\
\hline \multirow{4}{*}{2008} & \multirow{4}{*}{9} & \multirow{4}{*}{2011} & 1 & 4.34 & 3.43 & 4.19 & 4.38 & & & & 0 & 864 & 3,451 \\
\hline & & & 2 & & 4.05 & 4.58 & 3.96 & 4.74 & & & 0 & 846 & 3,371 \\
\hline & & & 3 & & & 5.00 & 4.39 & 5.10 & 5.77 & & 1 & 849 & 3,385 \\
\hline & & & 4 & & & & 3.77 & 3.56 & 5.23 & 4.66 & 2 & 822 & 3,277 \\
\hline
\end{tabular}

a. Summer Months are defined as from June to August.

b. The shaded areas in each row show the reference period for each rotation group in the wave when food insufficiency information is collected.

c. Monthly food insufficiency rate in the reference period for each rotation group is reported. 
Table 2. Weighted Sample Characteristics of Households Receiving Free/Reduced-price Lunch $(\mathrm{N}=15,241)$

\begin{tabular}{lr}
\hline \multicolumn{1}{c}{ Variables } & Mean or \% \\
\hline Dependent Variables & 6.91 \\
Four-month food insufficiency rate & 3.86 \\
Monthly food insufficiency rate & \\
Independent Variable & \\
Number of summer months & 32.99 \\
0 & 21.26 \\
1 & 29.10 \\
2 & 16.64
\end{tabular}

Covariates

Household head's characteristics

Age (mean) $\quad 40.71$

Gender (female) $\quad 64.33$

Race

White $\quad 66.42$

Black 26.75

Others 6.84

Married (Yes) $\quad 50.49$

Education

Below high school $\quad 28.48$ 
$\begin{array}{ll}\text { High school } & 31.04\end{array}$

$\begin{array}{ll}\text { Some college } & 32.85\end{array}$

$\begin{array}{ll}\text { Bachelor and above } & 7.63\end{array}$

$\begin{array}{ll}\text { Employed } & 68.53\end{array}$

Household characteristics

Household size (mean) $\quad 4.31$

$\begin{array}{ll}\text { Metro areas } & 77.35\end{array}$

Monthly income (mean, by thousand) 2.85

$\begin{array}{lr}\text { Public housing (Yes) } & 9.76\end{array}$

$\begin{array}{ll}\text { SNAP participation } & 38.01\end{array}$ 
Table 3. Food Insufficiency among Households Receiving Free/Reduced-price Lunch ( $=15241)$

\begin{tabular}{|c|c|c|c|c|c|c|c|c|}
\hline \multirow{3}{*}{ Variables } & Col 1: & Col 2: & Col 3: & Col 4: & Col 5: & Col 6: & Col 7: & Col 8: \\
\hline & Fixed- & Fixed- & Fixed- & Fixed- & Fixed- & Fixed- & & \\
\hline & effects $^{\mathrm{a}}$ & effects $^{\mathrm{a}}$ & effects $^{\mathrm{ab}}$ & effects $^{\mathrm{ac}}$ & effects $^{\mathrm{ad}}$ & effects $^{\mathrm{ae}}$ & Pooled OLS ${ }^{\text {af }}$ & Logit $^{\mathrm{fg}}$ \\
\hline \multicolumn{9}{|l|}{ Independent Variable } \\
\hline Indicator of summer months & $.007^{* *}$ & $.007^{* *}$ & $.007^{* *}$ & $.005^{*}$ & $.007^{*}$ & $.005^{*}$ & $.007^{* *}$ & $1.21^{* *}$ \\
\hline$(1=$ Yes $)$ & {$[0.01,0.12]$} & {$[0.01,0.12]$} & {$[.003, .012]$} & {$[.000, .010]$} & {$[.000, .014]$} & {$[.000, .009]$} & {$[.002, .012]$} & {$[1.07,1.37]$} \\
\hline \multicolumn{9}{|l|}{ Control Variables } \\
\hline \multirow[t]{2}{*}{ Order of the reference month } & .001 & .001 & $.002^{* *}$ & $.002^{*}$ & $.002^{* *}$ & .001 & .001 & 1.03 \\
\hline & {$[-.000, .002]$} & {$[-.000, .002]$} & {$[.001, .003]$} & {$[.000, .003]$} & {$[.000, .003]$} & {$[-.001, .002]$} & {$[-.001, .003]$} & {$[1.07,1.37]$} \\
\hline Household income (\$, by & & $-.002^{*}$ & $-.002^{* *}$ & -.002 & -.002 & -.001 & $-.004^{* * *}$ & $.82^{* * *}$ \\
\hline thousand) & & {$[-.004,-.000]$} & {$[-.004,-.000]$} & {$[-.007,-.000]$} & {$[-.004, .000]$} & {$[-.003, .001]$} & {$[-.004,-.003]$} & {$[.99,1.08]$} \\
\hline Household head's & & -.006 & -.006 & -.003 & .000 & -.006 & $-.016^{* * *}$ & $.76^{* * *}$ \\
\hline employment ( 1 = Yes) & & {$[-.018, .006]$} & {$[-.018, .006]$} & {$[-.017, .010]$} & {$[-.013, .015]$} & {$[-.020, .007]$} & {$[-.021,-0.12]$} & {$[.68, .86]$} \\
\hline Household head's marital & & $.026^{*}$ & $.026^{*}$ & .023 & $.031^{*}$ & .021 & -.005 & .93 \\
\hline status $(1=$ Yes $)$ & & {$[.002, .051]$} & {$[.002, .051]$} & {$[-.012, .058]$} & {$[.005, .057]$} & {$[-.008, .050]$} & {$[-.009, .000]$} & {$[.81,1.07]$} \\
\hline
\end{tabular}


Household head's age

Household head's gender

(1 = Female $)$

Household head's race

(reference group: White)

Black

Others

Household head's education

(reference group: below high

school)

High school

$\begin{array}{cc}.000 & 1.00 \\ {[-.000, .000]} & {[1.00,1.01]} \\ .008^{* * *} & 1.30^{* * *} \\ {[.004, .012]} & {[1.15,1.48]}\end{array}$

$$
-.000
$$$$
.97
$$$$
[-.005, .005] \quad[.85,1.10]
$$$$
.000
$$

$[-.007, .007]$

$$
-.007^{* * *}
$$

$[-.012,-.003]$ $[.74, .94]$ 
Some college

Bachelor and above

Household size

Metro areas $(1=$ Yes $)$

Public housing $(1=$ Yes $)$

Calendar years

(reference group: 1998)

2003

2005
$[-.008, .001] \quad[.83,1.06]$

$-.017^{* * *} \quad .54^{* * *}$

$[-.022,-.011] \quad[.41, .69]$

$.002^{* *} \quad 1.07^{* * *}$

$[.001, .003] \quad[1.03,1.11]$

$.007^{*} \quad 1.21^{*}$

$[.001, .012] \quad[1.04,1.41]$

$-.000$

.94

$[-.007, .006] \quad[.81,1.09]$

$.001 \quad 1.03$

$[-.007, .009] \quad[.83,1.27]$

$-.003$

.94

$[-.008, .003] \quad[.81,1.10]$ 
2010

2011

Number of Observations

60,776

60,776

60,776

30,757

15,241

15,241

15,241

$15,241=7,712$

$[-.008, .003] \quad[.80,1.10]$

$.009^{* *}$

$1.29^{* * *}$

$[.003, .015] \quad[1.10,1.50]$

60,776

60,776

a. Regression coefficient and 95\% confidence interval are reported for fixed-effects analyses and pooled OLS analysis.

b. This sensitivity test defined July as the only summer month.

c. This sensitivity test only included households with income not greater than $130 \%$ of the poverty line.

d. This sensitivity test included households with at least one child aged 5-11.

e. This sensitivity test included households with at least one child aged 12-18.

f. The analysis controls for indicators of states as well. Results on indicators of states are not reported in Table.

g. Odds ratio and 95\% confidence interval are reported for the logit analysis.

$* \mathrm{p}<.05, * * \mathrm{p}<.01, * * * \mathrm{p}<.001$ 
Figure 1. Food Insufficiency among Households Receiving Free/Reduced-price Lunch

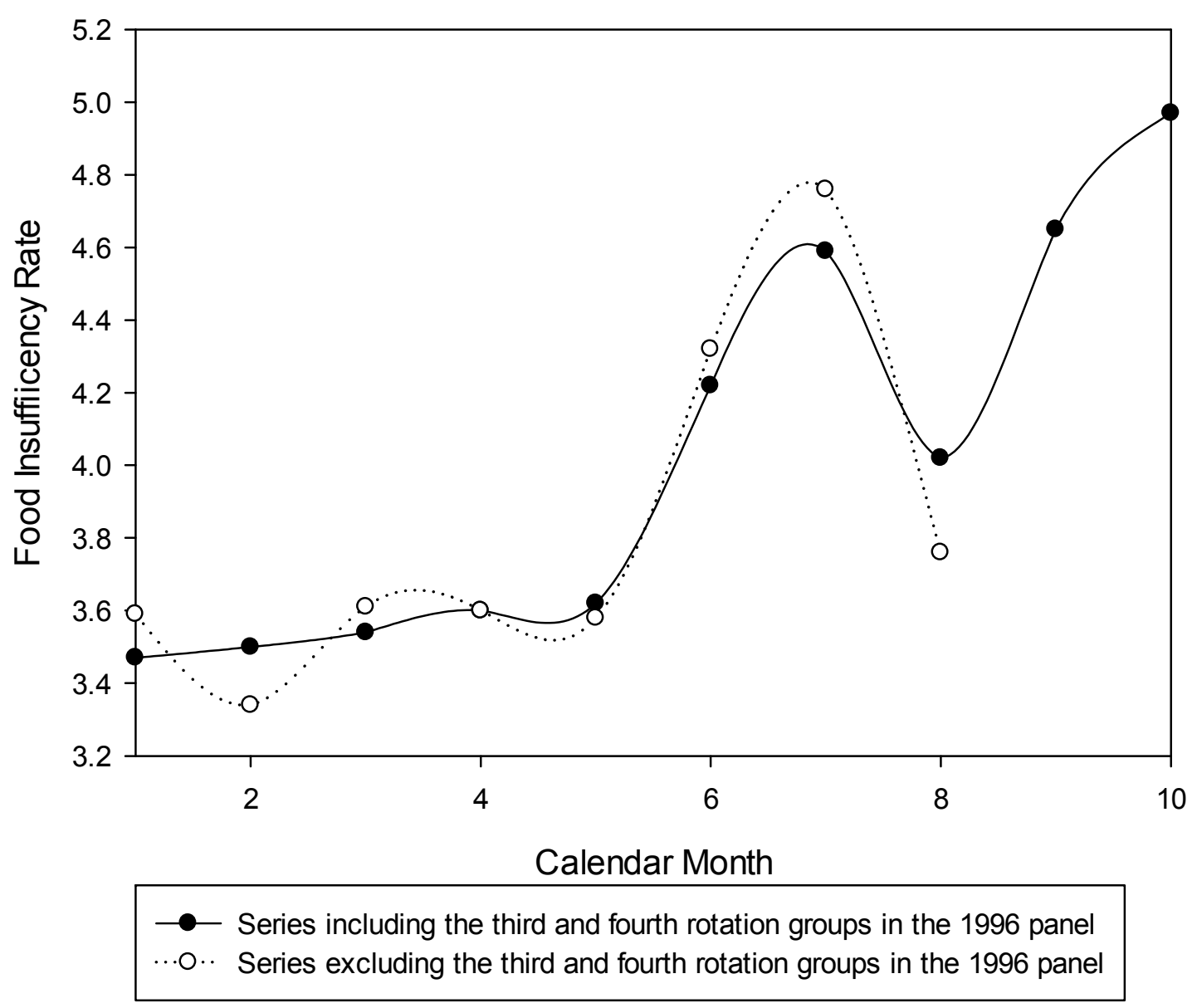

